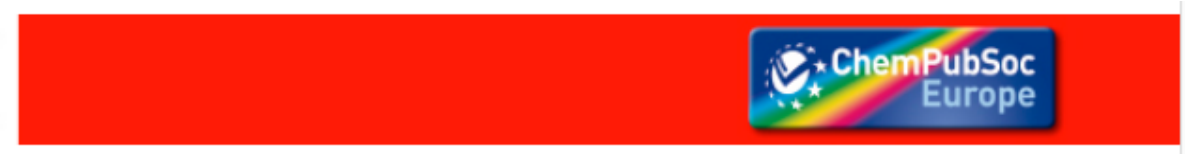

\title{
Aqueous Assembly of Zwitterionic Daisy Chains
}

Yves Aeschi, Sylvie Drayss-Orth, Michal Valášek, Daniel Häussinger, and Marcel Mayor*

[*] Y. Aeschi, Dr. S. Drayss-Orth, PD Dr. D. Häussinger, Prof. Dr. M. Mayor

Department of Chemistry

University of Basel

St. Johanns-Ring 19

4056 Basel, Switzerland

E-mail: $\underline{\text { marcel.mayor@unibas.ch }}$

Y. Aeschi, Prof. Dr. M. Mayor

Swiss Nanoscience Institute

University of Basel

Klingelbergstrasse 82

4056 Basel, Switzerland

Dr. M. Valášek, Prof. Dr. M. Mayor

Institute for Nanotechnology (INT)

Karlsruhe Institute of Technology (KIT)

P. O. Box 3640

76021 Karlsruhe, Germany

Prof. Dr. M. Mayor

Lehn Institute of Functional Materials (LIFM)

School of Chemistry

Sun Yat-Sen University (SYSU)

Guangzhou 510275, China 


\section{TOC Graphic:}

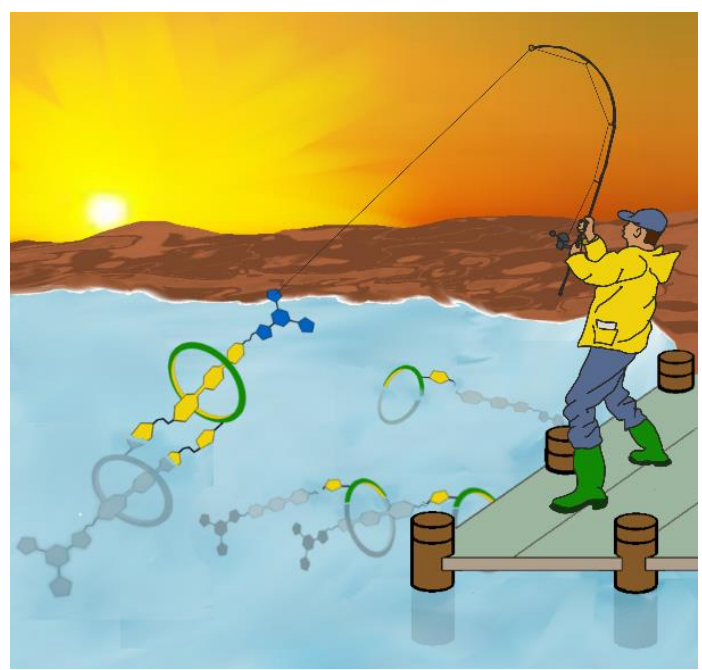

\section{Abstract}

The synthesis and characterization of zwitterionic molecular [c2]- and [a2]- daisy chains is described, relying on recognition of a positively charged cyclophane and a negatively charged oligophenyleneethynylene (OPE) rod in aqueous medium. For this purpose, syntheses of an acetylene-functionalized macrocyclic receptor and a water-soluble OPE-rod as guest component are presented, from which a heteroditopic daisy chain monomer is prepared. This monomer aggregates strongly in water/methanol 4:1 and forms molecular daisy chains, which are isolated as interlocked species from a stoppering reaction at $1 \mathrm{~mm}$ concentration. The cyclic dimer ([c2]) is the main product with an isolated yield of $30 \%$ and consists of a mixture of diastereomers, which is evidenced by ${ }^{1} \mathrm{H}-\mathrm{NMR}$ spectroscopy.

\section{Introduction}

Synthesis of rotaxanes, catenanes and derived structures thereof from dynamic host-guest assemblies has been accomplished by employment of various strategies. ${ }^{[1]}$ A plethora of such mechanically interlocked super-structures are known up to date, which upon introduction of stimuli-responsive features enabled chemists to obtain elaborate molecular machines. ${ }^{[2-4]}$ The 
stupendous development in this field was recently appreciated by awarding a Nobel Prize for the achievements in this research area. Introduction of rotaxane-type supramolecular subunits or even supramolecular machinery into materials chemistry ${ }^{[4,5]}$ and molecular electronics ${ }^{[6-8]}$ may give rise to the development of functional materials with unprecedented physical and/or chemical properties.

Covalently bound host-guest conjugates result in the formation of supramolecular daisy chains $^{[9-16]}$ if the molecular structures are designed appropriately to rule out unimolecular selfcomplexation and formation of non-interlinked, intermolecular aggregates. ${ }^{[16]}$ Due to the hermaphroditic nature of daisy chains, only one component is required for supramolecular complex formation, which is appealing for the construction of molecular devices as it is possible to obtain aggregates of different sizes by rational design, which was demonstrated by the synthesis of linear and cyclic molecular muscles, ${ }^{[12-14,17-19]}$ polymers ${ }^{[11,20-22]}$ and gels. ${ }^{[13,23,24]}$ Most daisy chains are based on recognition features which have only limited applicability in water, either due to limited solubility or functional disruption of the recognition site. This is striking as hydrophobic self-assembly is widespread in the biological realm, often in combination with other driving forces, such as hydrogen-bonding, donor-acceptor- and electrostatic interactions, ${ }^{\text {[25-27] }}$ which generates a sheer limitless, modular pool of supramolecular assemblies. Furthermore, exploitation of the hydrophobic effect as a driving force for supramolecular assembly is particularly appealing as no specialized recognition site is required, thus any hydrophobic surfaces will aggregate in aqueous environment. Limitations for hydrophobic assembly are mainly the solubility of host-guest complexes in aqueous environment in combination with sterically matching hydrophobic sites - two parameters which are often challenging to be both implemented. Furthermore, the lack of inherent specificity of hydrophobic interactions requires that lipophilic und hydrophilic properties are carefully balanced to avoid undesired aggregation modes.

In the context of daisy chains, aqueous assembly is so far mostly limited to systems based on cyclodextrin receptors. ${ }^{[16]}$ In spite of the wide availability and well-established chemistry, ${ }^{[28,29]}$ their synthetic modifiability is limited. An alternative, synthetically modifiable receptor for aqueous media is therefore desirable. The series of cyclophanes synthesized and extensively 
characterized by Diederich et.al. ${ }^{[30,31]}$ bind strongly to hydrophobic guests and show a high degree of synthetic flexibility. ${ }^{[32-35]}$ Rotaxane syntheses with these cyclophanes have been accomplished ${ }^{[36-39]}$ and high association constants with several guest molecules ${ }^{[37,39,40]}$ were reported. Due to their cationic nature, an additional electrostatic driving force can be expected by choosing guests with a complementary charge. ${ }^{[37]}$ Appropriate coupling chemistry is required to obtain interlocked species from the dynamic equilibrium, for which copper-catalyzed azidealkyne cycloaddition (CuAAC) click-chemistry is an ideal choice, allowing modular and efficient coupling in aqueous solutions as well as in organic solvents. ${ }^{[11,42]}$

We became interested in aqueous soluble daisy chain dimers as potential subunit of mechanically interlocked superstructures. The molecular design is based on the combination of a "Diederich"-type cyclophane and an oligophenyleneethynylene (OPE)-type rod comprising terminal salicyl-type synthons (see Figure 1 a). Both structures receive their water solubility from their peripheral ionic subunits and the attraction of the opposed charges further stabilize the pseudorotaxane complex. To obtain a monomer suitable for the formation of a daisy chain dimer however, the macrocyclic cyclophane and the OPE-type rod have to be tethered tightly to avoid the formation of an intramolecular "lasso-type" complex. ${ }^{[43,44]}$ The here presented approach is sketched in Figure $1 \mathrm{~b}$ ) and starts with the introduction of suitable coupling groups at both structures, the cyclophane and the OPE-rod. Their covalent linkage results in the desired monomer, which is expected to dimerize in aqueous solution to the daisy chain dimer in order to optimize the solvation conditions of all subunits. In a following step, similar coupling chemistry that allowed for the linkage of the subunits enables the introduction of bulky stoppers in order to freeze the supramolecular complex for its subsequent isolation and characterization.

Here we report the successful implementation of this concept by decorating the involved building blocks with functional groups enabling their covalent linking by CuAAC. The formation of supramolecular complexes is studied and the stoppered [c2]-daisy chain was isolated and characterized. 
a)

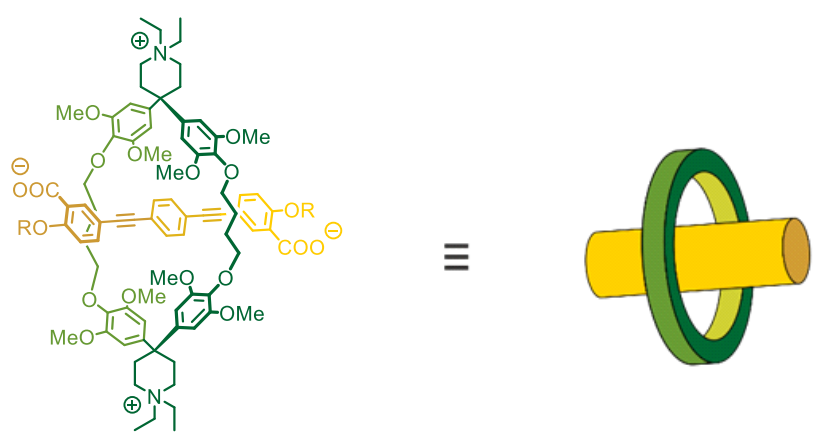

b)

$$
\mathrm{OPECCyOMe_{8 }}
$$

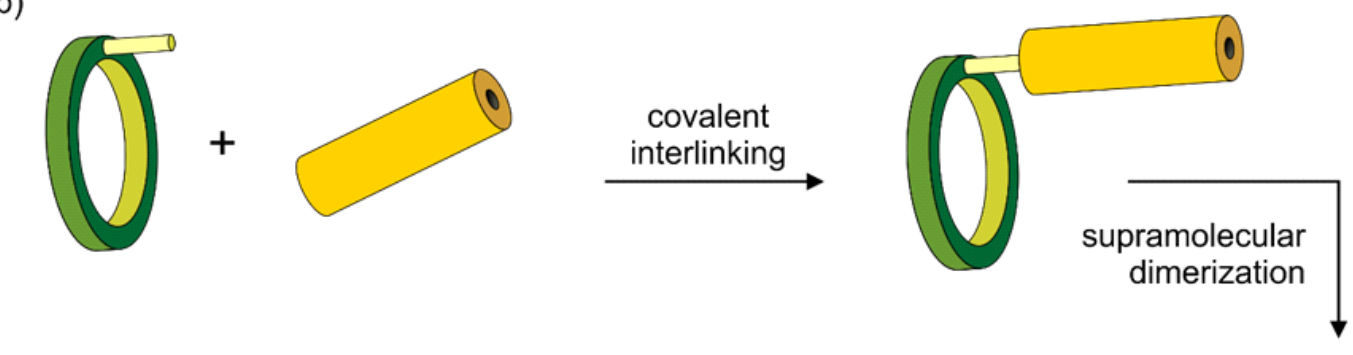

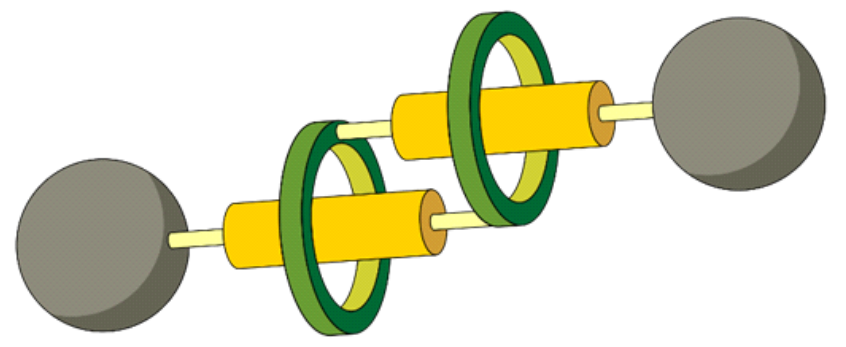

stoppered [c2]-daisy chain dimer

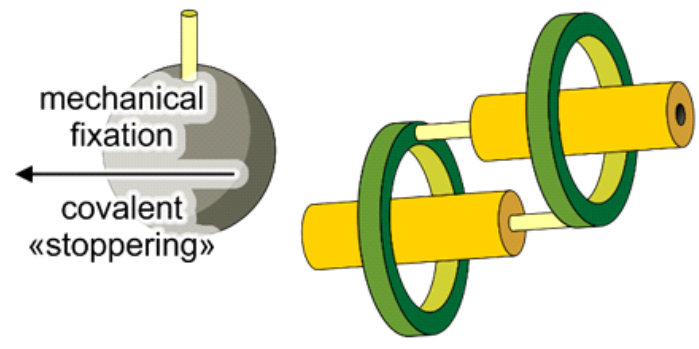

[c2]-daisy chain dimer

Figure 1. a) Pseudorotaxane formed by the combination of CyOMes, a "Diederich"-type cyclophane, and an OPErod with salicyl-type termini. b) Conceptual approach to water soluble and stable [c2]-daisy chain structures: The covalent linkage of axle and macrocycle results in a monomer, which forms [c2]-daisy chain dimers to satisfy the solvation requirements programed in the structure. The covalent attachment of bulky stoppers interlocks the mechanically interlinked structures.

\section{Results and Discussion}

Rigid, hermaphroditic receptor-guest-conjugate $\mathbf{1}$ can be obtained by tethering receptor $\mathbf{2}$ to rigid OPE rod 3 by CuAAC (Scheme 1). The rigidity of the OPE-subunit is expected to reduce the entropic penalty upon daisy chain formation, ${ }^{[16]}$ and disfavor intramolecular self-complexation. Such a unimolecular complexation mode would induce significant strain, while still exposing the hydrophobic parts of the OPE rod to the bulk water. $\mathbf{2}$ was designed on the basis of CyOMes, 
exposing a peripheral alkyne group, enabling its further decoration employing CuAAC strategies. Similar to the original design, the periphery is still decorated with methoxy groups which reduce the tendency of self-aggregation, ${ }^{[31]}$ while two quaternary ammonium centers provide solubility in water. Hydrophobic and hydrophilic properties of OPE-rod $\mathbf{3}$ are balanced by the presence of the two anionic carboxylate groups while its central phenylene unit remains as a highly hydrophobic station remote from the hydration shell of the carboxylate functions. Furthermore, the salicylate precursor can be functionalized with peripheral azide groups. Masking of the carboxylic acid as alkyl esters can be accomplished by standard esterification protocols, which ensures good processability during synthesis. Water-soluble stopper $\mathbf{4}$ allows to obtain either cyclic or acyclic interlocked daisy chains (5-[a2], 5-[c2]) from the dynamic equilibrium in aqueous solution. These can subsequently be separated and characterized as discrete entities. This stopper is a derivative of our precedent work, allowing to interlock supramolecular assemblies which incorporate a cyclophane with a comparable cavity size to CyOMe. ${ }_{8 .}{ }^{[39]}$

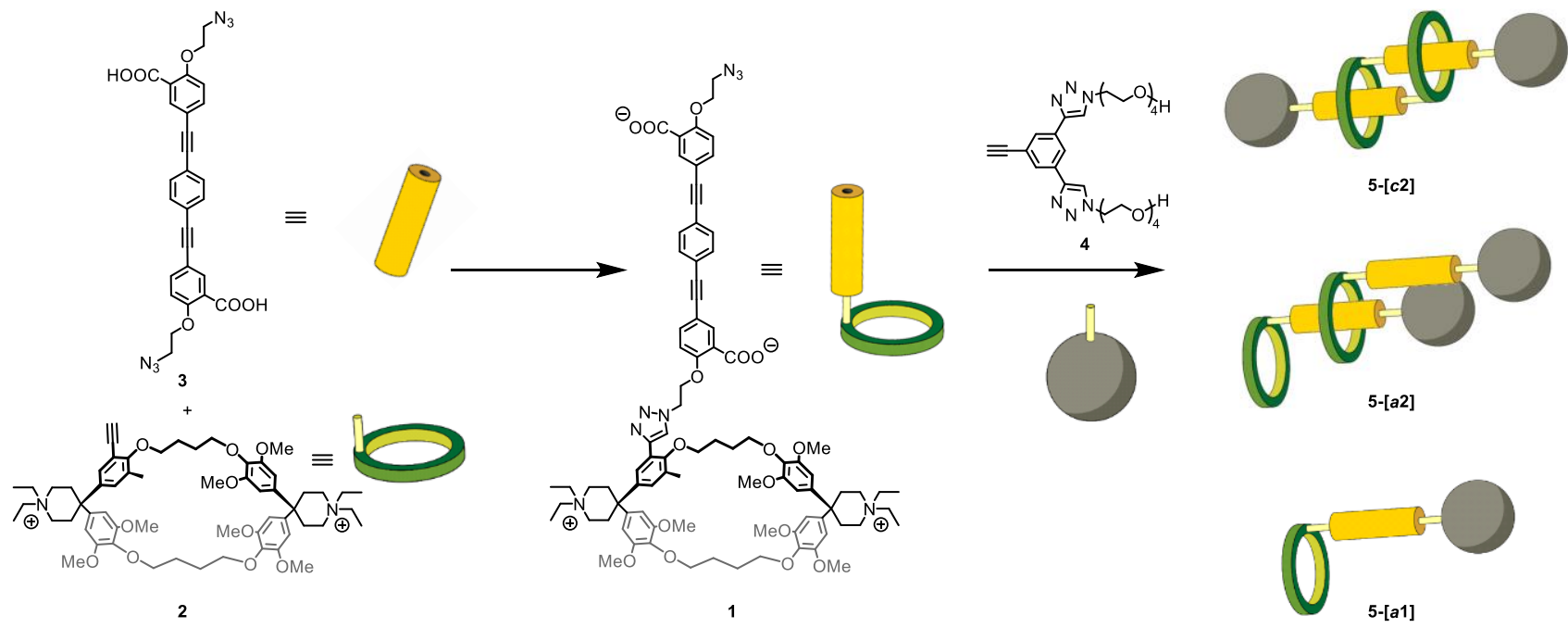

Scheme 1. Molecular structures of all building blocks for the assembly of daisy chains 5-[a2], 5-[c2] and stoppered monomer 5-[a1]. Molecular structures of daisy chains are given in Scheme 4. 

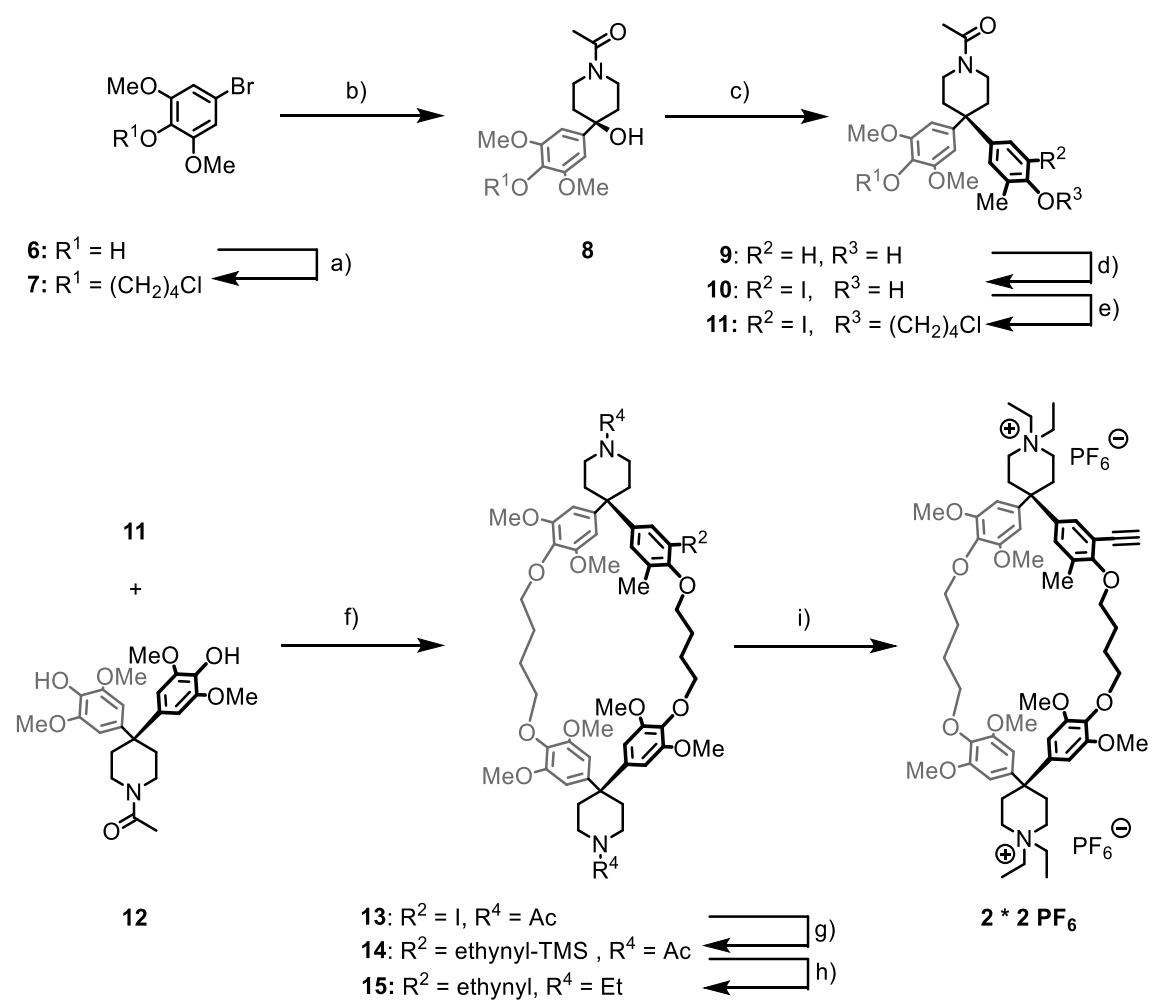

Scheme 2: Synthetic route towards cyclophane 2. (a) 1,4-dichlorobutane, $\mathrm{K}_{2} \mathrm{CO}_{3}, \mathrm{DMF}, 110{ }^{\circ} \mathrm{C}, 3 \mathrm{~h}, 94 \%$; (b) $i$-PrMgCl, $n$-BuLi, 1-acetyl-4-piperidone, THF, $-5{ }^{\circ} \mathrm{C}, 20 \mathrm{~min}, 52 \%$; (c) o-cresol, $\mathrm{BF}_{3} \times \mathrm{Et}_{2} \mathrm{O}$, r.t., DCM, $18 \mathrm{~h}, 90 \%$; (d) ICl ( $\mathrm{Nal} / \mathrm{NaOCl}$ ), $\mathrm{NaOH}, \mathrm{MeOH} / \mathrm{H}_{2} \mathrm{O}, 0{ }^{\circ} \mathrm{C}, 76 \%$ (quant.); (e) 1,4-dichlorobutane, $\mathrm{NaH}, \mathrm{DMF}, 50{ }^{\circ} \mathrm{C}, 6 \mathrm{~h}, 92 \%$; (f) $\mathrm{Cs}_{2} \mathrm{CO}_{3}$, DMF, $100{ }^{\circ} \mathrm{C}, 18 \mathrm{~h}, 41 \%$; (g) TMS-acetylene, THF, Et $3 \mathrm{~N}, \mathrm{Pd}\left(\mathrm{PPh}_{3}\right)_{2} \mathrm{Cl}_{2}, \mathrm{PPh}_{3} \mathrm{Cul}$, r.t., 20 h, 89 \%; (h) LiAlH $\mathrm{H}_{4}$ DIBAL-H, $\mathrm{THF},-10{ }^{\circ} \mathrm{C}, 30 \mathrm{~min}$, r.t., $30 \mathrm{~min}$, then $\mathrm{K}_{2} \mathrm{CO}_{3}, \mathrm{MeOH} / \mathrm{DCM}$, r.t., $30 \mathrm{~min}, 91 \%$; (i) Etl, THF, 4 d, r.t., then $\mathrm{KPF}_{6}, \mathrm{H}_{2} \mathrm{O}$, $97 \%$.

Receptor synthesis (Scheme 2): Synthesis of cyclophane $\mathbf{2}$ starts by alkylation of 4-bromosyringol (6) in DMF with 1,4-dichlorobutane in presence of potassium carbonate, furnishing 7 in $94 \%$ yield. Initial attempts to prepare $\mathbf{8}$ by lithiation of $\mathbf{7}$ followed by nucleophilic addition to 1 -acetyl-4piperidone resulted in rather low and poorly reproducible yields of the addition reaction regardless of the reaction temperature. Therefore, a Grignard reaction was attempted, starting with a bromine/magnesium exchange using the $(n-\mathrm{Bu})_{2}(i-\mathrm{Pr}) \mathrm{MgCl}$ magnesate complex ${ }^{[45]}$ in THF solution. Attempts to perform this reaction with $i-\mathrm{PrMgCl} \times \mathrm{LiCl}^{[46]}$ did not result in any metalation of the aryl bromide. The nucleophilic addition then resulted in formation of $\mathbf{8}$ in an acceptable and reproducible yield of $52 \%$. The following Friedel-Crafts alkylation of o-cresol with 8 in DCM 
with $\mathrm{BF}_{3} \times \mathrm{Et}_{2} \mathrm{O}$ as a Lewis acid furnished 9 in $90 \%$ yield. The choice for 0 -cresol over 2methoxyphenol in this step was simply due to the high regioselectivity of the Friedel-Craftsreaction compared to 2-methoxyphenol. For the latter, substitution in the 5-position (para to the methoxy group) always occurred to a small extent. This resulted in a mixture of regioisomers which could not be purified on a preparative scale. Ortho-iodination of the cresyl moiety in methanol/water under basic conditions with $\mathrm{ICl}$ afforded $\mathbf{1 0}$ in $76 \%$ yield after column chromatography (CC). On a small scale, 10 could be obtained in quantitative yield by in situgeneration of the electrophilic iodonium species, using sodium iodide and sodium hypochlorite. ${ }^{[47]}$ This reaction unfortunately tended to form poorly separable chlorinated species and oxidation products upon upscaling of the batch size. The following alkylation with an excess of 1,4-dichlorobutane was conducted in DMF solution using $\mathrm{NaH}$ as a base, which resulted in $92 \%$ yield for cleft 11. Intermolecular cyclization of $\mathbf{1 1}$ and bisphenol $\mathbf{1 2}$ in DMF in the presence of $\mathrm{Cs}_{2} \mathrm{CO}_{3}$ yielded 13 in $41 \%$ on a multigram scale, which is a typical yield for this type of cyclization. ${ }^{[35,36]}$ It was found that preheating of the oil bath and immediate, vigorous stirring is essential to obtain reproducible yields. Introduction of a TMS-protected acetylene by Sonogashira-cross-coupling in $\mathrm{DCM} / \mathrm{Et}_{3} \mathrm{~N}$ proceeded in a yield of $89 \%$ for 14 . This was followed by a reduction with a combination of $\mathrm{LiAlH}_{4} / \mathrm{DIBAL}-\mathrm{H}$ in THF at $-10^{\circ} \mathrm{C}$. The combination of both reagents and careful temperature control resulted in a clean conversion, avoiding incomplete reduction or $\mathrm{N}$-deacetylation which sometimes occurred when using DIBAL-H or $\mathrm{LiAlH}_{4}$ alone. As the silyl group was only partially cleaved during basic workup, complete desilylation was achieved in $\mathrm{DCM} / \mathrm{MeOH}$ solution in the presence of $\mathrm{K}_{2} \mathrm{CO}_{3}$, yielding $91 \%$ for 15 over both steps. Quaternization with ethyl iodide and subsequent precipitation from aqueous solution by addition of $\mathrm{KPF}_{6}$ afforded $\mathbf{2} * \mathbf{2} \mathbf{P F}_{6}$ in an excellent yield of $97 \%$. 

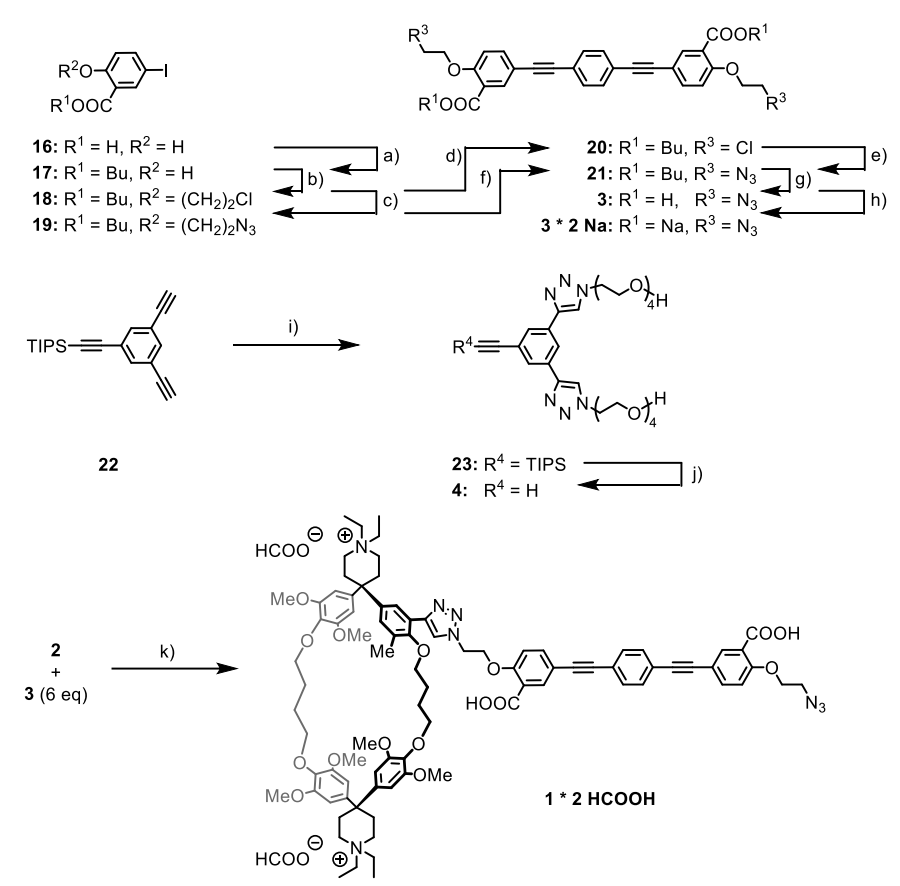

Scheme 3. Synthetic routes towards OPE 3, stopper 4 and daisy chain monomer 1 . (a) $n-\mathrm{BuOH}, \mathrm{H}_{2} \mathrm{SO}_{4}, \mathrm{cyclohexane}$, reflux, $2 \mathrm{~h}$, $78 \%$; (b) $\mathrm{Br}\left(\mathrm{CH}_{2}\right)_{2} \mathrm{Cl}, \mathrm{K}_{2} \mathrm{CO}_{3}$, DMSO, r.t., 3 d, 83 \%; (c) $\mathrm{NaN}_{3}$, DMSO, $80{ }^{\circ} \mathrm{C}, 2$ d, 88 \%; (d) 1,4-diethynylbenzene, $\mathrm{Pd}\left(\mathrm{PPh}_{3}\right)_{2} \mathrm{Cl}{ }_{2}, \mathrm{Cul}$, THF/Et ${ }_{3} \mathrm{~N}$, r.t. 30 min, $55 \%$; (e) $\mathrm{NaN}_{3}$, DMSO/PhMe, $120^{\circ} \mathrm{C} \mathrm{MW}$ irradiation, $2 \mathrm{~h}, 58 \%$; (f) 1,4-diethynylbenzene, $\mathrm{Pd}\left(\mathrm{PPh}_{3}\right)_{2} \mathrm{Cl} 2, \mathrm{Cul}$, $\mathrm{THF} / \mathrm{Et}_{3} \mathrm{~N}, 50{ }^{\circ} \mathrm{C}, 1 \mathrm{~d}, 63 \%$; (g) NaOH, $\mathrm{H}_{2} \mathrm{O} / \mathrm{MeOH} / \mathrm{THF}$, r.t., 20 h, then $\mathrm{HCl}, 99 \%$; (h) NaOH, $i$-PrOH/THF, $\mathrm{H}_{2} \mathrm{O}$, r.t. 90 min, 74 \%; (i) $\mathrm{H}\left(\mathrm{OC}_{2} \mathrm{H}_{4}\right)_{4} \mathrm{~N}_{3}$, TBTA, $\left[\mathrm{Cu}\left(\mathrm{CH}_{3} \mathrm{CN}\right)_{4}\right] \mathrm{PF}_{6}$, acetone, r.t., $30 \mathrm{~min}, 93 \%$; (j) TBAF, THF, r.t., 6 h, $79 \%$; (k) TBTA, $\left[\mathrm{Cu}\left(\mathrm{CH}_{3} \mathrm{CN}\right)_{4}\right] \mathrm{PF}$, DMF, $\mathrm{Et}_{3} \mathrm{~N}$, r.t., 24 h, 30-64\%.

Synthesis of hermaphroditic monomer 1, OPE-rod 3 and stopper 4 (Scheme 3): Esterification of commercially available 5-iodosalicylic acid (16) with $n$-butanol gave the butyl ester $\mathbf{1 7}$ in $\mathbf{7 8 \%}$ isolated yield. Alkylation of $\mathbf{1 7}$ with 1-bromo-2-chloroethane provided $\mathbf{1 8}$ in a yield of $83 \%$. Chloroethyl substituted OPE 20 was obtained by Sonogashira cross-coupling of 18 with 1,4diethynylbenzene in $55 \%$ yield. A nucleophilic substitution with sodium azide in DMSO/Toluene solution under microwave irradiation at $120^{\circ} \mathrm{C}$ afforded azidoethyl-substituted OPE $\mathbf{2 1}$ in $58 \%$ yield. Purification of this reaction mixture required extensive CC due to incomplete substitution and formation of byproducts with very similar retention times on silica gel. Fortunately, the situation improved considerably by treating $\mathbf{1 8}$ with sodium azide in DMSO, resulting in the azidefunctionalized OPE precursor 19 in an isolated yield of $88 \%$. Sonogashira cross-coupling of 19 with 1,4-diethynylbenzene afforded OPE-rod 21 in a yield of $63 \%$ after a short CC to remove 
catalyst residues. Subsequent basic ester hydrolysis in a mixture of water, methanol and THF followed by precipitation with hydrochloric acid afforded $\mathbf{3}$ in $99 \%$ yield. The sodium salt was obtained by reacting 3 in $i$-PrOH/THF suspension with aqueous $\mathrm{NaOH}$ and subsequent recrystallization from $\mathrm{H}_{2} \mathrm{O} / \mathrm{EtOH}$.

Acetylene-functionalized, water-soluble stopper 4 was obtained starting by a click reaction of $\mathbf{2 2}$ with tetra(ethylene glycol) monoazide in acetone, using tetrakis(acetonitrile)copper(I)-hexafluorophosphate with tris[(1-benzyl-1H-1,2,3-triazol-4-yl)methyl]amine (TBTA) as Cu(I)-stabilizing ligand. ${ }^{[48]}$ This procedure gave 23 in an excellent yield of $93 \%$ after $\mathrm{CC}$. Subsequent desilylation using TBAF in THF solution afforded 4 in $79 \%$ yield. The assembly of daisy chain monomer $\mathbf{1}$ was achieved in DMF by CuAAC of $\mathbf{2}$ with an excess of $\mathbf{3}$, using again tetrakis(acetonitrile)copper(I)-hexafluorophosphate and TBTA. Addition of triethylamine was crucial for an efficient transformation, presumably due to protonation of the $\mathrm{Cu}(\mathrm{I})$-stabilizing TBTA ligand by 3 in absence of a base. Surprisingly, attempts to isolate the reaction products by size exclusion chromatography on Sephadex LH-20 or C-25 failed. It was however possible to remove a major fraction of excess 3 prior to rigorous purification by preparative C-18 reversedphase chromatography. $1 * 2 \mathrm{HCOOH}$ was obtained in varying yields between $30 \%$ and $64 \%$ depending on the extent of purification required. $0.3 \%$ Formic acid was employed as buffer acid for the HPLC gradient (5\% to $90 \% \mathrm{CH}_{3} \mathrm{CN}$ in $\mathrm{H}_{2} \mathrm{O}$ in 13 minutes), fractions could be conveniently evaporated to dryness by rotary evaporation at heating bath temperatures of $25-30{ }^{\circ} \mathrm{C}$. When using trifluoroacetic acid the formation of decomposition products was observed during evaporation or upon standing. Usage of a basic additive such as triethylammonium bicarbonate hampered chromatographic resolution and was therefore no acceptable option. The quality of all fractions were analyzed prior and after evaporation. If any sign of impurities was detected by HPLC/ESI-MS, the purification procedure was either repeated or the fractions were discarded. The excessive purification of $\mathbf{1}$ was mandatory to avoid the formation of complex libraries of products in the synthesis of interlocked daisy chains. In order to obtain reproducible analytical HPLC chromatograms it was essential to employ a RP-C18 column which has either been in use for several weeks or to artificially age a new column. For reasons that we were not able to 
rationalize completely so far, 1 could either not be eluted or excessively high retention times were observed from new, previously unused columns. Interestingly, this peculiar behavior was exclusively observed for $\mathbf{1}$, while neither $\mathbf{2}$ nor $\mathbf{3}$ displayed a particular sensitivity to the history of the column.

Aggregation behavior: To gain insight into the association behavior of the subunits of 1 , the complexation behavior of OPE $3 * 2 \mathrm{Na}$ with $\mathrm{CyOMe}_{8} * \mathbf{2} \mathrm{Cl}$ was investigated as model system. An association constant of $4 \times 10^{6} \mathrm{M}^{-1}$ was determined by isothermal titration calorimetry, which was the expected high value considering the combination of hydrophobic complexation and the additional electrostatic contribution to the total binding strength (Figure SI 1). ${ }^{[37]}{ }^{1} \mathrm{H}-\mathrm{NMR}$ spectra of $3 * 2 \mathrm{Na}$ at $0.5 \mathrm{mM}$ concentration in $\mathrm{D}_{2} \mathrm{O}$ (Figure $\mathrm{SI} 2$ ) display a typical complexation-induced upfield shift of the phenylene protons from $\delta=7.6$ to 5.5 ppm upon addition of 1 eq of CyOMes * $\mathbf{2} \mathrm{Cl}$ as host. The more than 2 ppm shift is typical for aromatic protons encircled by $\mathrm{CyOMe}_{\mathbf{8}} * \mathbf{2}$ $\mathrm{Cl}$ and structurally related hosts at saturation binding in aqueous solution. ${ }^{[22]}$ As consequence of the high association constant, complexation reached saturation in this NMR experiment and no significant changes of the guest protons were observed upon further host addition, pointing at the expected predominant 1:1 host/guest stoichiometry. In the NMR sample with an excess of host, two separated sets of aryl signals for the complexed and uncomplexed host are observed, pointing at a slow exchange of the complexing host on the ${ }^{1} \mathrm{H}-\mathrm{NMR}$ timescale $(500 \mathrm{MHz})$. In conclusion, the complexation behavior of the subunits was promising and in analogy, a strong self-aggregation of 1 was expected in water displaying a slow exchange kinetics. Also promising was the conclusion, that an aggregation mode with more than one receptor moiety per OPE rod seemed unlikely for 1.

In spite of its tetraionic nature, 1 required addition of a significant proportion of an organic co-solvent as it precipitates from pure water. A water to methanol ratio of $4: 1$ turned out to be a good compromise for complexation studies. Qualitative interpretation of concentration dependent ${ }^{1} \mathrm{H}-\mathrm{NMR}$ spectra in 4:1 $\mathrm{D}_{2} \mathrm{O} / \mathrm{MeOD}$ (Figure 2) revealed that below $1 \mathrm{~mm}$, distinct resonances at about $\delta=5.4 \mathrm{ppm}$ occur. In analogy to the shifts observed in the model system ${ }_{3 \subset \mathrm{CyOMe}}$, these signals can be attributed to the phenylene moiety of the OPE rod being 
encircled by the cyclophane moiety. To get the chemical shifts of these hydrogens in an uncomplexed state, a sample of 1 with a concentration of $26 \mathrm{~mm}$ in a low polarity solvent mixture (THF- $\mathrm{d}_{8} / \mathrm{D}_{2} \mathrm{O}=4: 1$ ) was recorded. In that case no signals at $\delta=5.4 \mathrm{ppm}$ were detectable, but a singlet at $\delta=7.3 \mathrm{ppm}$ pointed at the complete dissociation of intermolecular complexes. Again, the complexation induced shift of approx. 2 ppm matches well with the observations in the model system ( $\left.3 \subset \mathrm{CyOMe}_{8}\right)$. In contrast to the model system however, the appearance of coupling patterns upon complexation reflects the unsymmetrical environment of the encircling receptor. Furthermore, the occurrence of more than one set of multiplets indicates the presence of more than one aggregate in the equilibrium. On the basis of the signals at $5.4 \mathrm{ppm}$, it seems that even at low concentrations like $50 \mu \mathrm{M}$, a significant degree of complexation occurs. Above a concentration of about $1 \mathrm{~mm}$, all peaks become increasingly broad, pointing at larger aggregates, either of longer interlinked daisy chain oligomers or of unspecific hydrophobic aggregates.

In conclusion, the aggregation studies corroborate the expected efficient assembly and aggregation of the molecular species involved. However, the structural and stoichiometric variety of possible aggregates does not allow to determine an association constant from ${ }^{1} \mathrm{H}-\mathrm{NMR}$ data for the desired supramolecular daisy chain dimer 1-[c2]. In order to gain insight into the structural variety of the species formed, the "stoppering" strategy displayed in figure 1 was applied to freeze the transiently formed superstructures mechanically. 


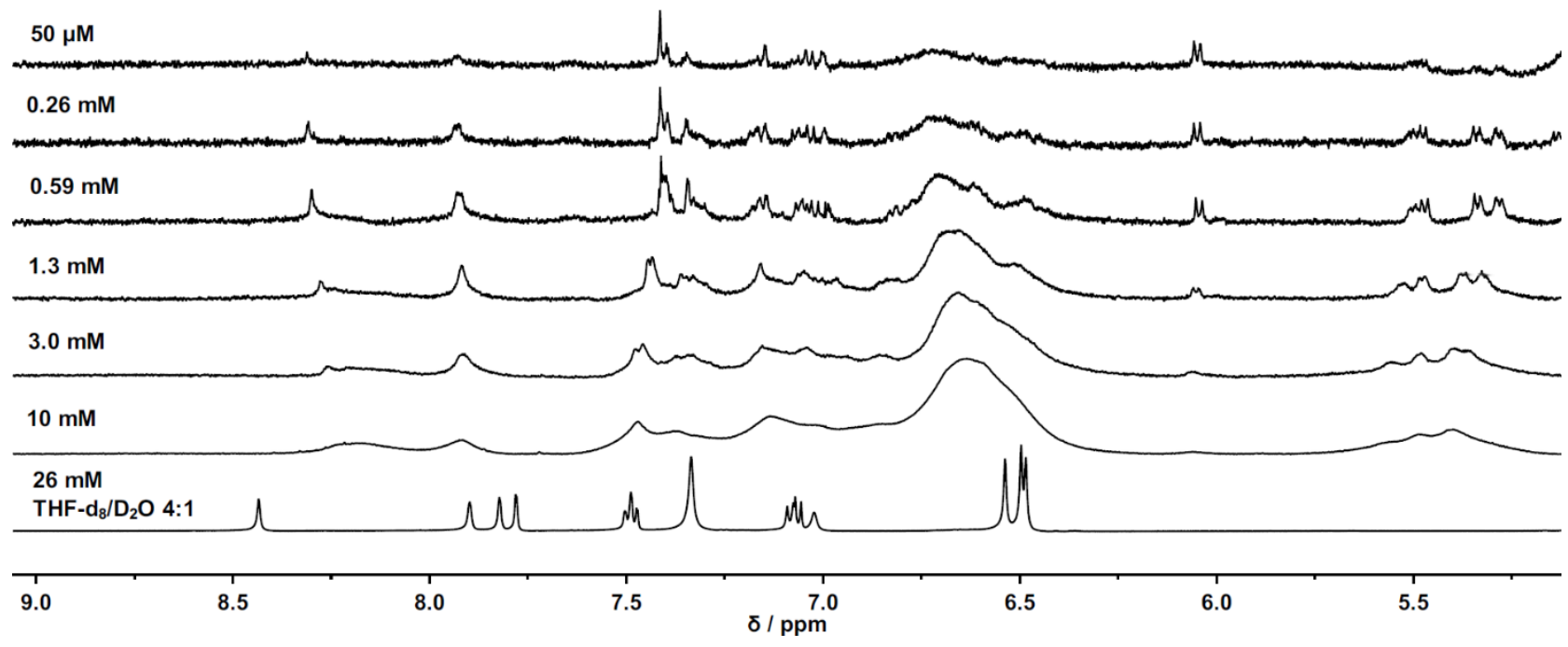

Figure 2. Concentration-dependent ${ }^{1} \mathrm{H}-\mathrm{NMR}$ spectra (500 MHz. expanded aromatic region) displaying the self-inclusion or aggregation behavior of 1 in $\mathrm{D}_{2} \mathrm{O} / \mathrm{MeOD}(4: 1)$ at $298 \mathrm{~K}$. For comparison, a ${ }^{1} \mathrm{H}-\mathrm{NMR}$ spectrum in an uncomplexed state $(600 \mathrm{MHz}$, 4:1 THF- $\left.\mathrm{d}_{8} / \mathrm{D}_{2} \mathrm{O}\right)$ is shown at the bottom.

Synthesis and characterization of interlocked daisy chains: Daisy chains were synthesized in a stoppering click reaction of 4 with 1 in $1 \mathrm{mM} \mathrm{H} \mathrm{H}_{2} \mathrm{O} / \mathrm{MeOH}$ (4:1) solution, using 1.5 equivalents of the stopper 4 (Scheme 4). As catalytic system, 50 mol\% copper(II) sulfate/tris\{[1-(3hydroxypropyl)-1H-1,2,3-triazol-4-yl]methyl\}amine (THPTA) ${ }^{[48]}$ in the presence of $15 \mathrm{~mm}$ sodium ascorbate were employed. The presence of $15 \mathrm{~mm}$ sodium carbonate served for $\mathrm{pH}$ stabilization. After 1 day of stirring, analysis of the crude mixture by HPLC/ESI-MS revealed first evidence for the formation of interlocked aggregates.

The HPLC/ESI-MS set-up allows not only the separation of the crude mixture into different fractions, it enables also to analyze the contribution of each band to a particular ion current. The UV signal and the total ion current displayed as the two top chromatograms of figure 3 display 4 peaks, from which the three later ones are labeled with colors and seem to have some broader signals as background. The first signal at about 6.5 minutes belongs to the residual unreacted stopper 4 . The identity of the remaining 3 peaks can be assigned by analyzing their contribution to a particular ion current. The panel representing the extracted ion current (EIC) 1052+ 
represents all structures able to make a signal with $\mathrm{m} / \mathrm{z}=1052$. These are all (super)structures consisting exclusively of the stoppered and doubly charged monomer, a criterion that can be satisfied by the doubly protonated monomer $(5-[a 1]+2 \mathrm{H})^{2+}$ itself, but also by the correspondingly fourfold protonated mechanically interlocked dimers $(5-[a 2]+4 \mathrm{H})^{4+}$ and $(5-[c 2]+4 \mathrm{H})^{4+}$. As consequence, the EIC $1052+$ chromatogram is fed by contributions from all 3 peaks of interest. Of course these are only the most prominent examples, any higher interlocked oligomer consisting of doubly protonated monomers also contribute to the EIC 1052+ chromatogram, what explains the additional weak and broad background in the panel. More selective is the next panel representing the contributors to EIC 701+. The signal represents the triply protonated monomer $(5-[a 1]+3 H)^{3+}$ and mechanically interlinked superstructures consisting thereof. However, a sixfold protonation of the dimeric superstructures is considerably less likely, and thus the contribution of $(5-[a 2]+6 H)^{6+}$ and $(5-[c 2]+6 H)^{6+}$ to the $701+$ signal are existing, but very minor. It thus becomes apparent that the last peak in the chromatogram (green in Fig. 3) belongs to the stoppered monomer 5-[a1]. For the peak assignment instrumental is the EIC 842+ signal, which belongs to fivefold protonated and interlocked dimers, as there is no charging state allowing the monomer to contribute. As displayed in figure 3, only the dark yellow and brown peak are contributing to this signal and thus, these two peaks are the mechanically interlocked dimers 5-[a2] and 5-[c2].

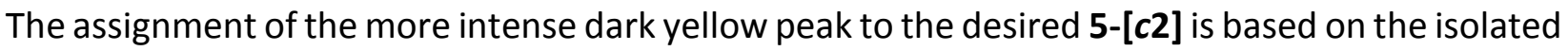
yields (see next section) and the rational that the dimer 5-[a2] resembles in its interaction with the column more the monomer 5-[a1] and is thus expected belonging to the peak with a retention time closer to the monomer. A similar argument can be made for 7 fold protonated trimeric superstructures resulting in an EIC of 902+. And indeed, the peaks contributing to the EIC 902+ suggest that the broad background signals of the chromatogram are mainly due to traces of mechanically interlocked higher oligomers. 


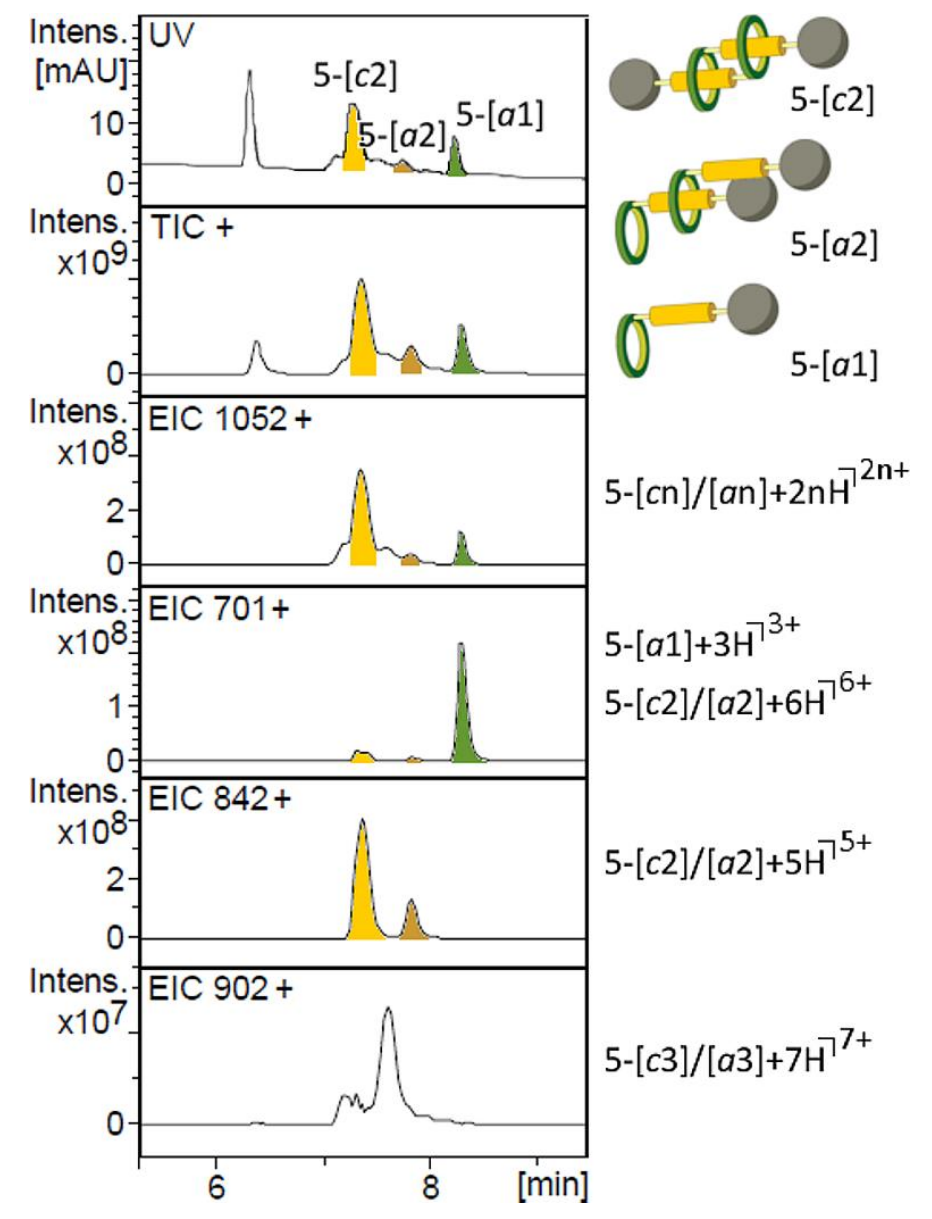

Figure 3. Analytical HPLC/ESI-MS traces of the crude stoppering reaction. From top to bottom: HPLC chromatogram (UV-Vis, 200-600 $\mathrm{nm}$; positive total ion current (TIC+); extracted positive ion currents (EIC, $\mathrm{m} / \mathrm{z}+$ ). The colored peaks were separated by preparative HPLC and the corresponding products were characterized. At $\sim 6.5 \mathrm{~min}$ retention time residual unreacted stopper is eluted.

The promising HPLC/ESI-MS analysis of the reaction mixture moved the isolation of the major superstructures into the focus of interest. Tedious purification by preparative C-18 reversedphase HPLC provided 5-[c2] * $4 \mathrm{HCOONH}_{4}$ in $30 \%$ yield, along with 5-[a2] * $\mathbf{4} \mathrm{HCOONH}_{4}(3.0 \%)$ and $7.3 \%$ of $5-[a 1] * 2 \mathbf{H C O O N H}_{4}$ (From this point, the ammonium formate content will be neglected in the product designations). Two impure fractions with trace amounts probably of a trimeric daisy chains were obtained as judged from LC/MS analysis. A total of 6 consecutive preparative HPLC runs were required to provide sufficient quantities for characterization. During each run $\left(\mathrm{H}_{2} \mathrm{O} / \mathrm{CH}_{3} \mathrm{CN}\right.$ gradient $20-70 \%$ in $25 \mathrm{~min}, 0.3 \%$ formic acid) 30 to 40 fractions were collected. All of them were analyzed by HPLC/ESI-MS and subjected to further purification if required. Rotary evaporation at $25{ }^{\circ} \mathrm{C}$ and neutralization of the dry product with ammonia solution allowed to maintain a fast workflow to avoid the appearance of decomposition products. After evaporation, all products required a mixture of THF or $\mathrm{CH}_{3} \mathrm{CN}$ and water to be readily 
soluble. They tended to form poorly soluble films on glass walls, which sometimes required several minutes to be dissolved. Similar to 1 , the daisy chains were susceptible to decomposition in the presence of trifluoroacetic acid and required aged HPLC columns to show reproducible retention times. No dissociation of the daisy chains to the monomeric species was observed during evaporation. 6-[a1] was equally susceptible to decomposition as 6-[a2]/[c2].

Characterization of the daisy chains: HRMS analysis confirmed the dimeric nature of 5-[a2], 5-[c2] and the monomeric nature of 5-[a1]. The identity of the compounds which were suspected to be trimers could unfortunately not be confirmed by HRMS. The two interlocked daisy chain species 5-[a2], 5-[c2] and the stoppered monomer 5-[a1] show distinctly different ${ }^{1} \mathrm{H}-\mathrm{NMR}$ spectra in the aromatic region (Scheme 4). As a global feature, all spectra comprise the expected signals from the stopper moiety between $\delta=8$ - 9 ppm. 5-[c2] could be identified by the absence of phenylene proton resonances at $\delta=7.3-7.6 \mathrm{ppm}$ and the appearance of signals between $\delta=$ $5.5-5.8 \mathrm{ppm}$, which occur as two separate sets of $A B$ coupling patterns. Their chemical shift and the appearance of coupling patterns strongly resemble the phenylene resonances in the dilution series of 1 in $\mathrm{D}_{2} \mathrm{O} / \mathrm{MeOD}$ (Figure 2). A 4:1 integration ratio of the combined phenylene resonances to the lowest-field triazole resonance of the stopper moiety confirms the cyclic dimeric structure. NOESY cross-peaks of the phenylene protons to the cavity aryl- and methoxy protons further corroborate the nature as an interlocked species. The occurrence of an AB coupling pattern of the phenylene moiety can be explained by a fast axial rotation within the unsymmetrical environment of the cyclophane. The two separate sets of phenylene AB resonances suggest that 5-[c2] was isolated as a mixture of its meso form and chiral diastereomers. ${ }^{[9,49]}$ This was found to occur in other examples of daisy chains composed of unsymmetrical subunits. ${ }^{[50-52]} A$ 1:1 integration ratio between the two AB-systems reveals that no diastereoselective assembly occurs despite the relatively rigid nature of 1 . The different chemical shift of the complexed phenylene protons indicates a different spatial arrangement of the OPE rods within the cavity. Thus it can be 
concluded that the alkyl linkage between OPE-rod and cyclophane provides enough flexibility to allow the formation of two equally stable [c2]-daisy chains. Other doubled signals with equal integration ratios but less pronounced differences in chemical shift were observed for the stopper- and salicyl moieties of the OPE rod (See Figure SI-45 - 48). Most remarkable is a set of split resonances belonging to the diastereotopic methylene protons of the two methylene units between cyclophane and OPE rod. This can be explained by a hindered rotation within the sterically crowded, unsymmetrical environment between the cyclophane cavities. In contrast, the rotation of the methylene units between OPE rod and stopper is unrestricted, therefore the diastereotopic protons are indistinguishable. 5-[a2] could be identified by the presence of one set of doublets of the OPE resonances between $\delta=5.5$ and $5.7 \mathrm{ppm}$ as well as of a singlet remaining at $7.41 \mathrm{ppm}$. These signals affirm the presence of one complexed and one uncomplexed OPE rod. In addition to this, the resonances of the cavity aryl protons are split into one set of occupied, low-field resonances and unoccupied, high field resonances. Due to the small amount of this substance available, no satisfactory NOESY/ROESY spectra could be recorded. 5[a1] can clearly be distinguished from the interlocked species by the absence of any phenylene signals around $\delta=5.5 \mathrm{ppm}$. The phenylene proton resonance occurs as a singlet at a comparable shift (7.44 ppm) to the spectrum of 1 . Diffusion constants obtained from DOSY NMR reveal similar diffusion constants for 5-[a2] and 5-[c2] which were much smaller than for 5-[a1]. The active volumes obtained from the diffusion constants provided a 3.2 times larger value for the mechanically interlocked dimer 5-[c2] and 3.7 times larger volume for 5-[a2] compared to the stoppered monomer 5-[a1]. While the slightly more compact nature of 5-[c2] compared to 5-[a2] is reflected in the slightly smaller hydrodynamic radius, the active volumes for both dimers are, based on the monomer, considerably larger than expected. For the compact arrangement in the interlocked superstructures a smaller value than twice the monomer volume was anticipated. While the measurement confirms a larger hydrodynamic radius of the dimeric daisy chains, the surprising extent of the increase might be caused by concentration effects and/or differences in solvation. The interlocked daisy chains did not exhibit any deslipping behavior upon storage in the NMR solvent $\left(\mathrm{CD}_{3} \mathrm{CN} / \mathrm{D}_{2} \mathrm{O} 10: 1\right)$ at room temperature for several days, confirming the efficacy of stopper $\mathbf{4}$ to disrupt supramolecular exchange. 


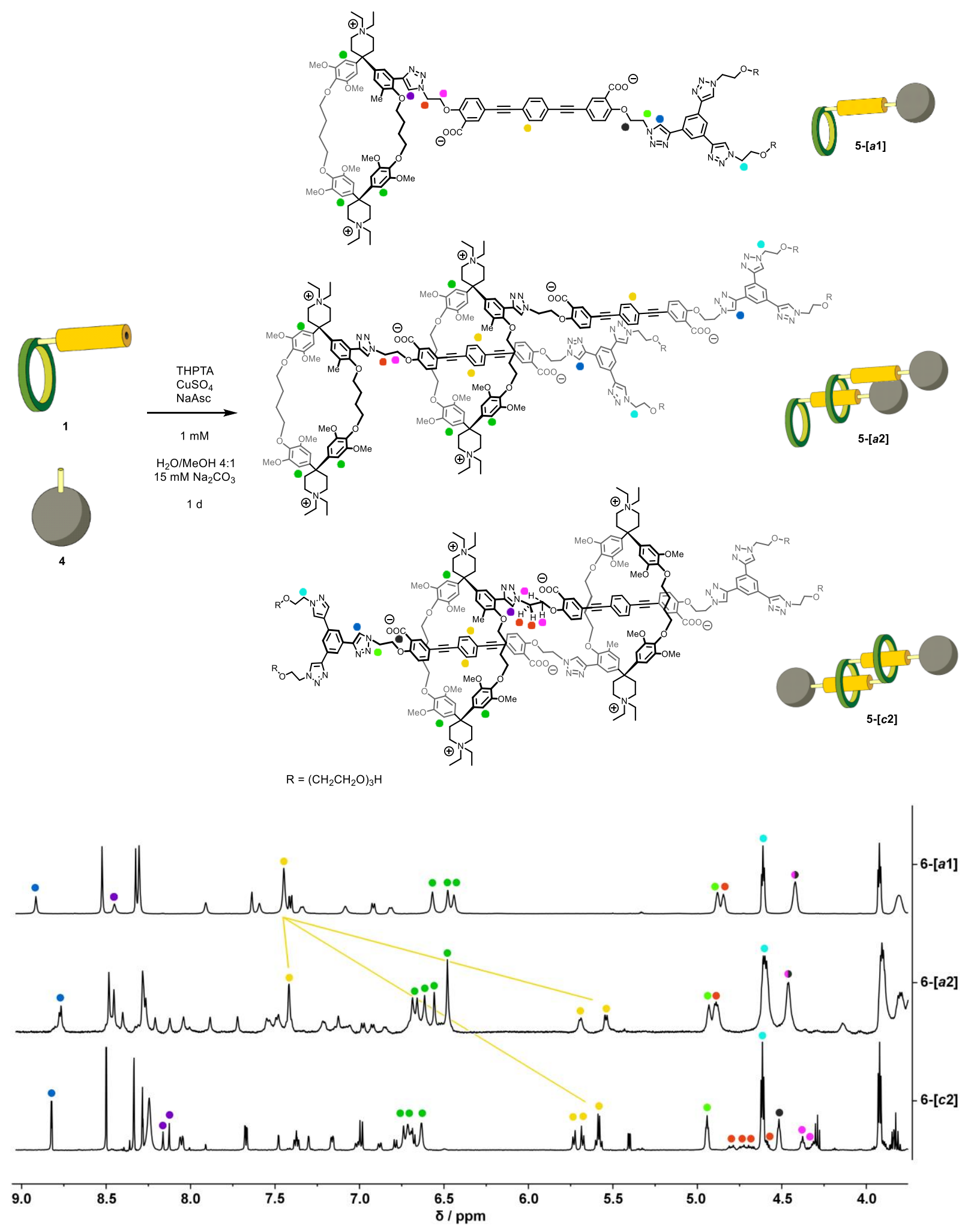

Scheme 4.Top: molecular structures of 5-[a1] (meso form shown representative for all 3 isomers), 5-[a2] and 5-[c2]. Bottom: ${ }^{1} \mathrm{H}-$ NMR spectra $\left(600 \mathrm{MHz}, C D_{3} C N / D_{2} \mathrm{O}=10: 1\right)$ of the three species above. Assignments of the peaks for 5-[a1] and 5-[c2] are based 
on NOESY spectra and integration ratios. For 5-[a2] it was required to rely on integration ratios and comparison to the first two compounds.

The UV-Vis and fluoresence spectra are very comparable for all three isolated stoppered compounds 5-[a1], 5-[a2], and 5-[c2]. As displayed in figure 4, the UV-Vis spectra of all three compounds have the absorption maxima at $332 \mathrm{~nm}$ and a shoulder at $359 \mathrm{~nm}$ is clearly visible for both mechanically interlocked dimers (5-[a2] and 5-[c2]) but is also adumbrated for the stoppered monomer 5-[a1]. In analogy, also the fluorescence spectra of the three compounds are comparable and display emission maxima at $367 \mathrm{~nm}$ with a shoulders at $385 \mathrm{~nm}$ (Figure 4, solid lines). While no shift of the emission peaks was observed upon complexation, the intensity of the emission signal increases with the number of complexed OPE subunits. The symmetric 5[c2] with both rods inside a cyclophane displayed the most intense signal and the monomeric 5[a1] with its OPE rod exposed to the solvent displayed the weakest emission signal. While the variation of the emission intensity was expected, the complete absence of a shift of the signal came as a surprise. During the preliminary investigations, the subunit OPE $\mathbf{3} * \mathbf{2}$ Na was titrated with $\mathrm{CyOMe}_{8} * 2 \mathrm{Cl}$ (Figure SI 4) and displayed both, a decrease of approximatealy $50 \%$ of the emission intensity of the broad signal at $387 \mathrm{~nm}$ and the emergence of a hypsochromically shifted peak at $381 \mathrm{~nm}$. Concentration-dependent emisson specta were also recorded from the unstoppered precursor 1 in $\mathrm{H}_{2} \mathrm{O} / \mathrm{MeOH}=4: 1$ (Figure $\mathrm{SI} 18$ ). These spectra resemble those of the stoppered daisy chains, displaying an emission maximum at $367 \mathrm{~nm}$ with a shoulder at $383 \mathrm{~nm}$. After correcting the recorded spectra for the concentration dependent optical density, no additional variation of the emission intensities due to aggregation was observed for 1 . In summary, both, the mechanically fixed isolated model compounds 5-[a2] and 5-[c2] as well as the free and stoppered monomer 1 and 5-[a1] showed only very minor aggregation induced 
variations of their optical spectra in the solvent mixture of interest $\left(\mathrm{H}_{2} \mathrm{O} / \mathrm{MeOH}=4: 1\right)$ and are thus not suited for titration experiments monitored by optical spectroscopy.

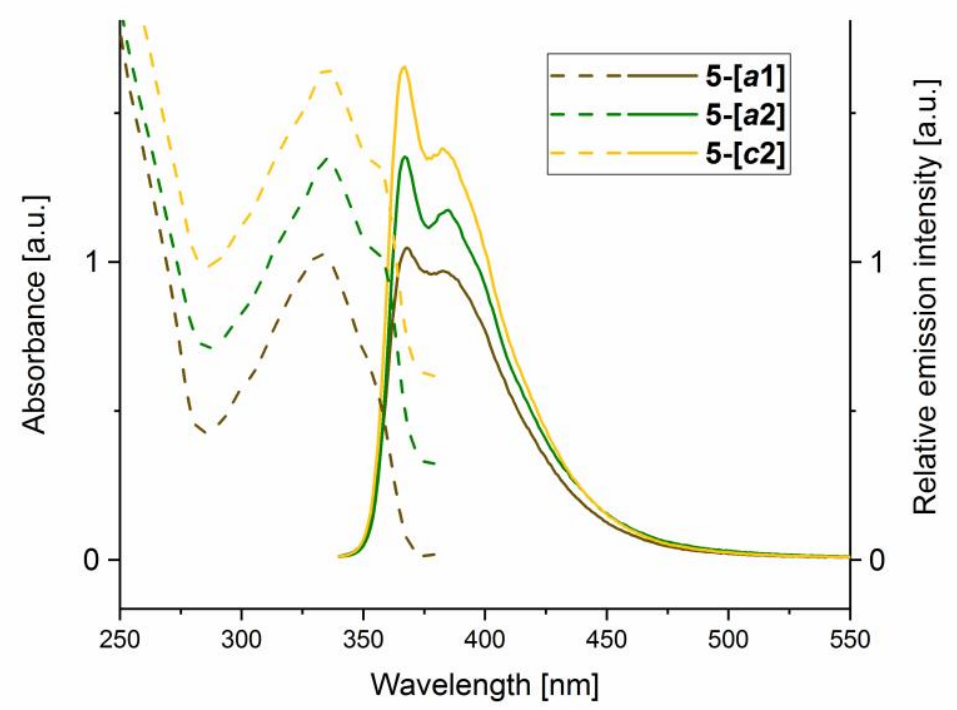

Figure 4. UV-Vis absorption spectra (dotted lines) and emission spectra (solid lines) of $0.1 \mu \mathrm{M}$ 5-[a2], $0.1 \mu \mathrm{M}$ 5-[c2], and $0.2 \mu \mathrm{M}$ 5 -[a1] in $\mathrm{H}_{2} \mathrm{O} / \mathrm{MeOH}=4: 1$, measured with $\lambda_{\mathrm{ex}}=332 \mathrm{~nm}$. Absorption spectra are normalized and offset in line with the emission maxima. The relative intensities of the emission spectra were corrected for differences in the optical density at $332 \mathrm{~nm}$. Absorption coefficients at $\lambda=332 \mathrm{~nm} \varepsilon\left(\mathrm{L} \mathrm{mol}^{-1} \mathrm{~cm}^{-1}\right)=5-[a 1], 0.5 \times 10^{5} ; 5-[a 2], 1.0 \times 10^{5} ; 5-[c 2], 1.3 \times 10^{5}$.

\section{Conclusion}

Interlocked molecular daisy chains 5-[c2] and 5-[a2] were assembled from zwitterionic precursor 1 and stopper 4. As a consequence of the short, flexible linkage between cyclophane and OPE, entropically favored [c2]-daisy chains were obtained as the main product. By NMR spectroscopy, the interlocked nature of both daisy chains could be verified and further corroborated by HRMS. The [c2]-daisy chains were obtained as a 1:1 mixture of meso/chiral diastereomers as evidenced by NMR analysis. 1 represents one of the few examples from which interlocked daisy chains comprising a rigid, extended $\pi$-conjugated rod were synthesized. ${ }^{[14]}$ To the best of our knowledge this is the only example where this could be accomplished in aqueous environment. A small 
amount of organic additive was still required to achieve significant solubility which is a consequence of the large organic structure combined with the zwitterionic character of the molecule. The yield of [c2]-daisy chains in this work was respectable, though isolation was handicapped due the extensive purification protocol and challenging stability features of the compounds. Strong associations are recorded for both, the daisy-chain precursor $\mathbf{1}$ and for the separated subunits $\mathbf{3}$ and $\mathrm{CyOMe}_{\mathbf{8}}$. The combination of high association constants and peripheral azide- and alkyne functionalization makes the building blocks presented herein promising building blocks for the assembly of mechanically interlocked molecules in aqueous environments.

\section{Acknowledgments}

Support for NMR measurements from Claudio Meyer and Thomas Müntener is gratefully acknowledged. Felix Fleckenstein is acknowledged for synthetic support during his practical course and Dr. Loïc LePleux for proofreading the manuscript. Generous financial support by the Swiss Nanoscience Institute (SNI grant number P1303) and the Swiss National Science Foundation (SNF grant number 200020-178808) are gratefully acknowledged.

\section{Experimental}

Experimental details and synthetic procedures of all daisy chain precursors are given in the electronic supporting information.

\section{Synthesis of daisy chains 5-[a1], 5-[a2] and 5-[c2]:}

Sodium carbonate $(26.2 \mathrm{mg}, 0.248 \mathrm{mmol})$ and $1 * 2 \mathrm{HCOOH}(26.5 \mathrm{mg}, 16.5 \mu \mathrm{mol})$ were dissolved in $15 \mathrm{~mL} \mathrm{H} \mathrm{H}_{2} \mathrm{O} / \mathrm{MeOH} \mathrm{4:1,} \mathrm{sonicated} \mathrm{for} 1 \mathrm{~min}$ and stirred for $10 \mathrm{~min}$ giving a clear solution. The catalyst was prepared separately by dissolving copper(II)-sulfate heptahydrate (2.1 mg, $8.3 \mu \mathrm{mol}$, $0.5 \mathrm{eq})$, sodium-L-ascorbate $(6.5 \mathrm{mg}, 33 \mu \mathrm{mol}, 2 \mathrm{eq})$ and tris\{[1-(3-hydroxypropyl)-1H-1,2,3triazol-4-yl]methyl\}amine (3.6 mg, $8.3 \mu \mathrm{mol} 0.5 \mathrm{eq}$ ) in $\mathrm{H}_{2} \mathrm{O} / \mathrm{MeOH}$ 4:1 $(1.5 \mathrm{~mL})$. Both solutions were degassed with a stream of Ar for $2 \mathrm{~min}$ and then vigorously stirred. It was stirred for 3 days at room temperature in the absence of light. The solvent was removed in vacuo at a heating bath 
temperature of $30{ }^{\circ} \mathrm{C}$. The crude mixture was redissolved in $\mathrm{H}_{2} \mathrm{O} / \mathrm{CH}_{3} \mathrm{CN}$ 5:1 $+0.3 \%$ formic acid (4.5 mL) and subjected to preparative RP-C18 HPLC (from 20 to $70 \% \mathrm{CH}_{3} \mathrm{CN}$ in $\mathrm{H}_{2} \mathrm{O} 25$ minutes) in 2 runs in equal portions. Final purification was then achieved by an additional 4 consecutive preparative HPLC runs. Before each run, the $\mathrm{pH}$ of the solution was checked to match the starting conditions on the HPLC column. The fractions were analyzed by HPLC/ESI-MS, combined and evaporated to dryness as fast as possible by rotary evaporation with a bath temperature of 25-30 ${ }^{\circ} \mathrm{C}$. After evaporation, the product was redissolved in a small amount of $\mathrm{CH}_{3} \mathrm{CN} / \mathrm{H}_{2} \mathrm{O}(2: 1)$, neutralized by a few drops of $25 \%$ ammonia solution and then evaporated to give the daisy chains 5-[a2] * $4 \mathrm{HCOONH}_{4}(1.1 \mathrm{mg}, 3.0 \%)$ and 5-[c2] * 4 HCOONH$_{4}(11 \mathrm{mg}, 30 \%)$ and the stoppered monomer 5-[a1] * $2 \mathrm{HCOONH}_{4}$ (2.7 mg, $7.3 \%$ ), total yield $40.3 \%$. HPLC chromatograms, detailed NMR- and HR-mass spectra are given in the supporting information (Pages SI-24-45).

Keywords: daisy chain, rotaxane, cyclophane, hydrophobic complexation, click-chemistry

\section{References}

[1] M. Xue, Y. Yang, X. Chi, X. Yan, F. Huang, Chem. Rev. 2015, 115, 7398-7501.

[2] J. F. Stoddart, Angew. Chem. Int. Ed. 2017, 56, 11094-11125.

[3] S. Erbas-Cakmak, D. A. Leigh, C. T. McTernan, A. L. Nussbaumer, Chem. Rev. 2015, 115, 10081-10206.

[4] C. J. Bruns, J. F. Stoddart, Acc. Chem. Res. 2014, 47, 2186-2199.

[5] L. Fang, M. A. Olson, D. Benítez, E. Tkatchouk, W. A. Goddard III, J. F. Stoddart, Chem. Soc. Rev. 2010, 39, 17-29.

[6] H. Wen, W. Li, J. Chen, G. He, L. Li, M. A. Olson, A. C.-H. Sue, J. F. Stoddart, X. Guo, Sci. Adv. 2016, 2, e1601113-e1601113.

[7] W. Zhang, S. Gan, A. Vezzoli, R. J. Davidson, D. C. Milan, K. V. Luzyanin, S. J. Higgins, R. J. Nichols, A. Beeby, P. J. Low, et al., ACS Nano 2016, 10, 5212-5220.

[8] X. Li, D. Hu, Z. Tan, J. Bai, Z. Xiao, Y. Yang, J. Shi, W. Hong, Top. Curr. Chem. 2017, 375, DOI 10.1007/s41061-017-0123-x. 
[9] P. R. Ashton, I. Baxter, S. J. Cantrill, M. C. T. Fyfe, P. T. Glink, J. F. Stoddart, A. J. P. White, D. J. Williams, Angew. Chem. Int. Ed. 1998, 37, 1294-1297.

[10] M. C. Jiménez, C. Dietrich-Buchecker, J.-P. Sauvage, A. De Cian, Angew. Chem. Int. Ed. 2000, 39, 1295-1298.

[11] S. J. Rowan, S. J. Cantrill, J. F. Stoddart, A. J. P. White, D. J. Williams, Org. Lett. 2000, 2, 759762.

[12] C. J. Bruns, J. Li, M. Frasconi, S. T. Schneebeli, J. Iehl, H.-P. Jacquot de Rouville, S. I. Stupp, G. A. Voth, J. F. Stoddart, Angew. Chem. Int. Ed. 2014, 53, 1953-1958.

[13] K. Iwaso, Y. Takashima, A. Harada, Nat. Chem. 2016, 8, 625-632.

[14] J.-C. Chang, S.-H. Tseng, C.-C. Lai, Y.-H. Liu, S.-M. Peng, S.-H. Chiu, Nat. Chem. 2016, 9, 128134

[15] X. Fu, Q. Zhang, S.-J. Rao, D.-H. Qu, H. Tian, Chem. Sci. 2016, 7, 1696-1701.

[16] J. Rotzler, M. Mayor, Chem. Soc. Rev. 2013, 42, 44-62.

[17] M. C. Jiménez, C. Dietrich-Buchecker, J.-P. Sauvage, Angew. Chem. 2000, 39, 3284-3287.

[18] J. Wu, K. C.-F. Leung, D. Benítez, J.-Y. Han, S. J. Cantrill, L. Fang, J. F. Stoddart, Angew. Chem. 2008, 120, 7580-7584.

[19] C. J. Bruns, M. Frasconi, J. Iehl, K. J. Hartlieb, S. T. Schneebeli, C. Cheng, S. I. Stupp, J. F. Stoddart, J. Am. Chem. Soc. 2014, 136, 4714-4723.

[20] E. N. Guidry, J. Li, J. F. Stoddart, R. H. Grubbs, J. Am. Chem. Soc. 2007, 129, 8944-8945.

[21] M. Fathalla, N. L. Strutt, S. Sampath, K. Katsiev, K. J. Hartlieb, O. M. Bakr, J. Fraser Stoddart, Chem. Commun. 2015, 51, 10455-10458.

[22] P. G. Clark, M. W. Day, R. H. Grubbs, J. Am. Chem. Soc. 2009, 131, 13631-13633.

[23] A. Goujon, G. Mariani, T. Lang, E. Moulin, M. Rawiso, E. Buhler, N. Giuseppone, J. Am. Chem. Soc. 2017, 139, 4923-4928.

[24] A. Goujon, T. Lang, G. Mariani, E. Moulin, G. Fuks, J. Raya, E. Buhler, N. Giuseppone, J. Am. Chem. Soc. 2017, 139, 14825-14828.

[25] B. W. Ninham, V. Yaminsky, Langmuir 1997, 13, 2097-2108.

[26] M. Vendruscolo, C. M. Dobson, Nat. Chem. Biol. 2013, 9, 216-217. 
[27] J. J. McManus, P. Charbonneau, E. Zaccarelli, N. Asherie, Curr. Opin. Colloid Interface Sci. 2016, 22, 73-79.

[28] J. Szejtli, Chem. Rev. 1998, 98, 1743-1754.

[29] T. Girek, J. Incl. Phenom. Macrocycl. Chem. 2012, 74, 1-21.

[30] F. Diederich, Angew. Chem. Int. Ed. Engl. 1988, 27, 362-386.

[31] S. B. Ferguson, E. M. Sanford, E. M. Seward, F. Diederich, J. Am. Chem. Soc. 1991, 113, 54105419.

[32] F. Diederich, D. R. Carcanague, Angew. Chem. Int. Ed. Engl. 1990, 29, 769-771.

[33] E. M. Seward, R. B. Hopkins, W. Sauerer, S. W. Tam, F. Diederich, J. Am. Chem. Soc. 1990, $112,1783-1790$.

[34] D. R. Benson, R. Valentekovich, F. Diederich, Angew. Chem. Int. Ed. Engl. 1990, 29, 191-193.

[35] J. Rotzler, S. Drayss, O. Hampe, D. Häussinger, M. Mayor, Chem. Eur. J. 2013, 19, 2089-2101.

[36] S. Anderson, R. T. Aplin, T. D. W. Claridge, T. Goodson III, A. C. Maciel, G. Rumbles, J. F. Ryan, H. L. Anderson, J. Chem. Soc. Perkin Trans. 1 1998, 2383-2398.

[37] P. N. Taylor, A. J. Hagan, H. L. Anderson, Org. Biomol. Chem. 2003, 1, 3851.

[38] S. Anderson, T. D. W. Claridge, H. L. Anderson, Angew. Chem. Int. Ed. Engl. 1997, 36, 13101313.

[39] Y. Aeschi, S. Drayss-Orth, M. Valášek, F. Raps, D. Häussinger, M. Mayor, Eur. J. Org. Chem. 2017, 4091-4103.

[40] D. R. Benson, J. Fu, C. K. Johnson, S. W. Pauls, D. A. Williamson, J. Org. Chem. 1998, 63, 99359945.

[41] M. Meldal, C. W. Tornøe, Chem. Rev. 2008, 108, 2952-3015.

[42] K. D. Hänni, D. A. Leigh, Chem Soc Rev 2010, 39, 1240-1251.

[43] C. Clavel, C. Romuald, E. Brabet, F. Coutrot, Chem. Eur. J. 2013, 19, 2982-2989.

[44] Y. Wang, J. Sun, Z. Liu, M. S. Nassar, Y. Y. Botros, J. F. Stoddart, Chem. Sci. 2017, 8, 25622568.

[45] K. Kitagawa, A. Inoue, H. Shinokubo, K. Oshima, Angew. Chem. Int. Ed. 2000, 39, 2481-2483. 
[46] A. Krasovskiy, P. Knochel, Angew. Chem. Int. Ed. 2004, 43, 3333-3336.

[47] K. J. Edgar, S. N. Falling, J. Org. Chem. 1990, 55, 5287-5291.

[48] T. R. Chan, R. Hilgraf, K. B. Sharpless, V. V. Fokin, Org. Lett. 2004, 6, 2853-2855.

[49] S. J. Cantrill, G. J. Youn, J. F. Stoddart, D. J. Williams, J. Org. Chem. 2001, 66, 6857-6872.

[50] F. Coutrot, C. Romuald, E. Busseron, Org. Lett. 2008, 10, 3741-3744.

[51] J. Voignier, J. Frey, T. Kraus, M. Buděšínský, J. Cvačka, V. Heitz, J.-P. Sauvage, Chem. Eur. J. 2011, 17, 5404-5414.

[52] E. M. G. Jamieson, F. Modicom, S. M. Goldup, Chem. Soc. Rev. 2018, 47, 5266-5311 